\title{
Effect of In Situ Thermal Annealing on Structural, Optical, and Electrical Properties of CdS/CdTe Thin Film Solar Cells Fabricated by Pulsed Laser Deposition
}

\author{
Alaa Ayad Al-mebir, ${ }^{1,2}$ Paul Harrison, ${ }^{1}$ Ali Kadhim,, Guanggen Zeng, ${ }^{1}$ and Judy Wu ${ }^{1}$ \\ ${ }^{1}$ Department of Physics and Astronomy, University of Kansas, Lawrence, KS 66045, USA \\ ${ }^{2}$ Department of Physics, College of Education for Pure Science, Thi-Qar University, Nassiriya, Thi-Qar, Iraq \\ Correspondence should be addressed to Alaa Ayad Al-mebir; alaa_ash28@yahoo.com and Judy Wu; jwu@ku.edu
}

Received 6 November 2015; Revised 28 January 2016; Accepted 1 February 2016

Academic Editor: Veer P. S. Awana

Copyright ( 92016 Alaa Ayad Al-mebir et al. This is an open access article distributed under the Creative Commons Attribution License, which permits unrestricted use, distribution, and reproduction in any medium, provided the original work is properly cited.

An in situ thermal annealing process (iTAP) has been introduced before the common $e x$ situ cadmium chloride $\left(\mathrm{CdCl}_{2}\right)$ annealing to improve crystal quality and morphology of the CdTe thin films after pulsed laser deposition of CdS/CdTe heterostructures. A strong correlation between the two annealing processes was observed, leading to a profound effect on the performance of $\mathrm{CdS} / \mathrm{CdTe}$ thin film solar cells. Atomic force microscopy and Raman spectroscopy show that the iTAP in the optimal processing window produces considerable CdTe grain growth and improves the CdTe crystallinity, which results in significantly improved optoelectronic properties and quantum efficiency of the CdS/CdTe solar cells. A power conversion efficiency of up to $7.0 \%$ has been obtained on thin film CdS/CdTe solar cells of absorber thickness as small as $0.75 \mu \mathrm{m}$ processed with the optimal iTAP at $450^{\circ} \mathrm{C}$ for 10-20 min. This result illustrates the importance of controlling microstructures of CdTe thin films and iTAP provides a viable approach to achieve such a control.

\section{Introduction}

Cadmium Telluride (CdTe) has long been recognized as the second lowest-cost material after $\mathrm{Si}$ in the world photovoltaic market [1], specifically for thin film solar cells. The two attractive properties of CdTe are its nearly ideal band gap of $\sim 1.5 \mathrm{eV}$ for single $\mathrm{p}-\mathrm{n}$ junction photovoltaic and its high optical absorption coefficient up to $10^{5} \mathrm{~cm}^{-1}$. Therefore, a thickness of $\sim 1 \mu \mathrm{m}$ of CdTe can absorb almost $90 \%$ of the incident light. Despite the exciting progress made in commercializing CdS/CdTe solar cells using low-cost growth techniques for CdTe film production including electrodeposition [2], spray pyrolysis [3], and close space sublimation (CSS), the typical CdTe film thickness is in the range of $3 \mu \mathrm{m}$ to $8 \mu \mathrm{m}$ [4] at high growth temperatures around $\sim 600^{\circ} \mathrm{C}$ due to the issue of through-thickness pinholes at smaller thickness. This issue must be addressed in order to achieve high-performance thin film (thickness $\sim 1 \mu \mathrm{m}$ or less) CdS/CdTe solar cells. From the economic point of view, reducing CdTe usage in CdTe thin film solar cells could lower material cost, extend the tellurium supply which has a limited reserve, and also reduce the environmental footprint of the hazardous material, such as $\mathrm{Cd}$ [5]. In addition, smaller CdTe thickness provides advantages in reduced charge recombination.

The key to high-performance thin film CdTe-based solar cells is controlling microstructure of the CdS/CdTe through obtaining high-quality crystalline CdTe thin films that have low density pinholes and other defects and form high-quality p-n heterojunction interfaces on the CdS or other window layers [6]. Considering these, the relative high temperatures used for CdTe thick film growth may not be suitable in the thin film case due to lack of control in CdTe microstructure evolution. Therefore, development of low-temperature processes for CdTe thin film solar cells is important to achieving a precise control of the CdS/CdTe microstructure and optoelectronic properties. In addition, low temperatures provide benefits in wider selection of substrates especially those for low-cost, flexible solar cells applications [7]. Pulsed laser 


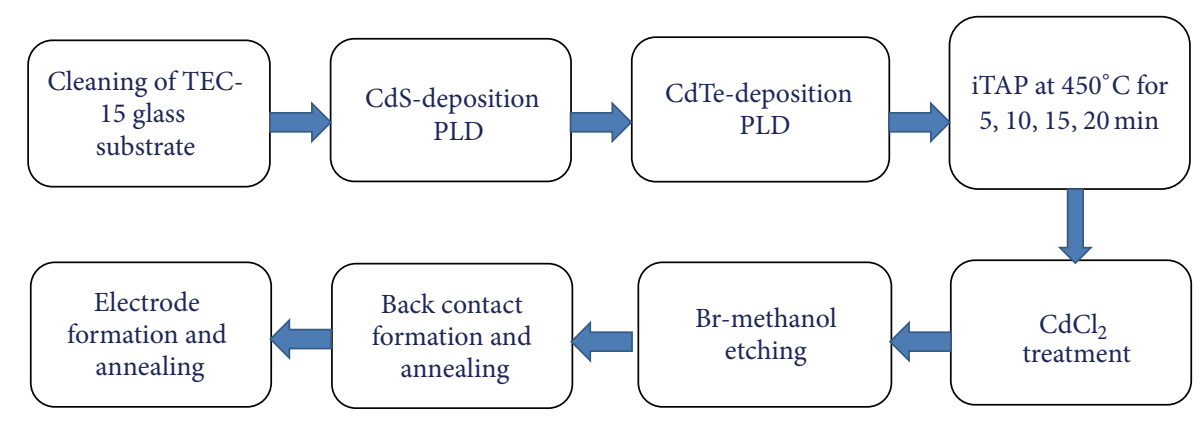

Figure 1: Schematic description of the key steps in CdS/CdTe solar cell fabrication including PLD deposition of CdS/CdTe heterostructures, followed with iTAP and posttreatments.

deposition (PLD) is a relatively new fabrication technique applied for CdTe solar cells. In PLD, in situ fabrication of CdS and CdTe thin film heterostructures can be achieved, which differs from most previous work of ex situ fabrication of CdTe solar cells. PLD is advantageous for thin film CdTe solar cell depositions considering its many easily adjustable processing parameters including laser repetition rate and energy density, target-substrate distance, pressure, and sample temperature. A systematic study of the effect of the PLD processing conditions is hence important to understanding the growth mechanism and optimizing performance of the CdTe solar cells. In our recent studies of PLD CdTe solar cells, we have found that the substrate temperature can sensitively affect the microstructure of devices $[8,9]$. Specifically, since PLD CdS must be carried out at lower temperatures around $15-200^{\circ} \mathrm{C}$, in situ raising temperatures to higher values of $450-550^{\circ} \mathrm{C}$ for $\mathrm{CdTe}$ growth often results in interchemical diffusion across the CdS/CdTe interface. In order to address this issue, we have developed an in situ thermal annealing process (iTAP) immediately after the CdS/CdTe deposition using PLD at $200^{\circ} \mathrm{C}$ and before the common ex situ $\mathrm{CdCl}_{2}$ annealing typically employed for optimization of the CdTe-based solar cells. A systematic study on the microstructure and optical and optoelectronic properties of $\mathrm{CdS} / \mathrm{CdTe}$ solar cells processed under different iTAP conditions has been carried out. It has been found that these physical properties depend sensitively on the iTAP processing conditions and appropriate iTAP in the optimal window enhances grain growth, improves grain boundary connectivity, and reduces crystal defects. This leads to considerably improved CdTe crystallinity and as a result improved optoelectronic properties of the $\mathrm{CdS} / \mathrm{CdTe}$ solar cells. Our result suggests that the iTAP is important for optimizing the chemical composition and microstructure of CdTe thin films and its heterojunction with CdS, both of which are critical to the performance of the CdS/CdTe thin film solar cells.

\section{Experimental Details}

Fabrication of the window (CdS) and absorber (CdTe) layers was carried out in a PLD system using a $248 \mathrm{~nm} \mathrm{KrF}$ excimer laser with $20 \mathrm{~ns}$ laser pulse duration [9-11]. The incident laser beam of pulse energy in the range of 140-150 mJ was directed at 45 degrees on the target (CdS and CdTe in this work) surface, producing a rapid temperature rise $\left(>10^{11} \mathrm{KS}^{-1}\right)$, and the generated plume carries a stoichiometric coating on the substrates [12]. The laser energy densities were 0.7 and $0.6 \mathrm{~J} / \mathrm{cm}^{2}$ at the CdTe and CdS targets, respectively. The PLD chamber base pressure was around $5 \times 10^{-6}$ mTorr and the deposition was conducted under an argon (purity $99.999 \%$ ) atmosphere of $\sim 1.5$ mTorr. FTO coated Glass substrates (TEC 15 with sheet resistance of $12-14 \mathrm{ohm} / \mathrm{sq}$.) were used as the front contact. Both CdS and CdTe targets (ACI Alloys with purity 99.99 at.\%) were installed at a distance of about $5.5 \mathrm{~cm}$ from the substrates and in situ switch of the targets was accomplished using a computer controlled motorized target carousel. The targets were also rotating at about $30 \mathrm{rpm}$ during the deposition. The repetition rate was $10 \mathrm{~Hz}$ and the substrate temperature was $200^{\circ} \mathrm{C}$ for PLD of CdS/CdTe bilayers.

Figure 1 describes the major steps in the CdS/CdTe solar cell fabrication process. After completing in situ PLD of CdS $(120 \mathrm{~nm}) / \mathrm{CdTe}(1.5 \mu \mathrm{m})$ bilayers, the samples were subjected to the iTAP at $450^{\circ} \mathrm{C}$ for $5,10,15$, and $20 \mathrm{~min}$. durations in 20 Torr Argon. Afterwards, the samples were removed from the PLD chamber and annealed in $\mathrm{CdCl}_{2}$ vapor in a tube furnace at $360^{\circ} \mathrm{C}$ for $15 \mathrm{~min}$. with a flow of mixed gas of $\mathrm{Ar}$ $(100 \mathrm{sccm})$ and $\mathrm{O}_{2}(25 \mathrm{sccm})$. Bromine etching was carried out after the $\mathrm{CdCl}_{2}$ annealing by placing the films into a mixing solution of $0.1 \mathrm{~mL} \mathrm{Br}$ and $100 \mathrm{~mL}$ methanol for 4 seconds and then rinsed directly with methanol, acetone, and DI water. Finally, the back contact paste of $\mathrm{HgTe}: \mathrm{Cu}$ : graphite was placed onto the CdTe surface to form 30 solar cells total on each sample. The samples were further annealed at $280^{\circ} \mathrm{C}$ for $30 \mathrm{~min}$. in a $100 \mathrm{sccm}$ Ar flow to cure the paste. Ag paste was then applied to the back contact for electrode formation, followed with annealing in a tube furnace at $100^{\circ} \mathrm{C}$ for $60 \mathrm{~min}$. to improve contact of the electrode to the back contact. Figure 2 shows the final structure of superstrate configuration of the fabricated CdS/CdTe solar cells.

\section{Results and Discussion}

The thickness of the films was measured using a profiler (KLA-Tencor P16). Atomic force microscopy (AFM) and Raman spectroscopy were employed to analyze the sample morphology and crystallinity. The optical transmittance of 


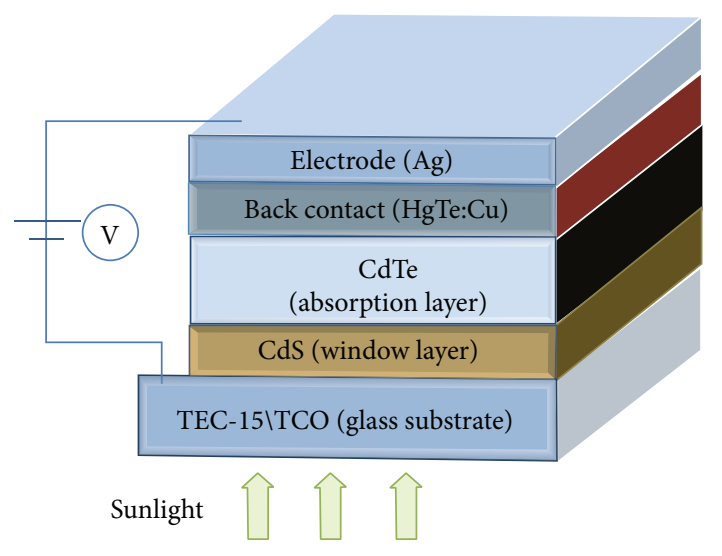

FIGURE 2: Superstrate configuration of the fabricated CdS/CdTe thin film solar cells.

the samples was characterized using a UV-Vis-NIR spectrophotometer (PerkinElmer Lambda 950) within the spectral range of $300-900 \mathrm{~nm}$. The performance of the solar cells was measured by using a CHI660D electrochemical workstation, a solar simulator at 1.5 AM, and a Newport 69911 spectrometer.

The AFM micrographs of the as-deposited CdTe layer and four other devices processed at different iTAP conditions are compared in Figure 3. The as-deposited sample without any iTAP treatment has a smooth surface and a small grain size of $\sim 50 \mathrm{~nm}$, which is larger than the grain size of $\sim 8.26 \mathrm{~nm}$ reported on CdTe films fabricated using imprinting and the electrodeposition method [13]. The larger grain size in PLD CdTe films may be attributed to the relatively high kinetic energy of atoms carried by the PLD plume, which is expected to enhance two-dimensional growth. In addition, the lower substrate temperature used in PLD is also beneficial to prevent $3 \mathrm{D}$ crystallization in an uncontrollable fashion, which explains much smaller grain size in PLD CdTe films as opposed to that of 3-4 $\mu \mathrm{m}$ in the CdTe thick films deposited at $\sim 600^{\circ} \mathrm{C}$ in the CSS process [14]. Obtaining CdTe grain size smaller than the targeted film thickness is important to producing a continuous thin film at small thickness and preventing local island-type aggregation.

The iTAP evidently promotes grain growth as shown in Figures 3(b)-3(e) and the grain growth increases monotonically with the iTAP duration at the fixed temperature of $450^{\circ} \mathrm{C}$. With $5 \mathrm{~min}$. iTAP duration, the grain size increased to $\sim 200 \mathrm{~nm}$ with appearance of many rounded facets (Figure 3(b)). By increasing the iTAP duration to $10 \mathrm{~min}$., even larger grain size of $\sim 300 \mathrm{~nm}$ can be seen in Figure 3(c), and a strong reaction seemed to occur where one could observe liquid-like coalescence and the formation of some voids. When the iTAP time is further increased to $15 \mathrm{~min}$. and $20 \mathrm{~min}$., respectively, as shown in Figures 3(d) and 3(e), the formation of crystallized CdTe film with many large faceted crystallites can be clearly seen and grain size is $\sim 500 \mathrm{~nm}$ with increased number of voids.

As a consequence of the microstructure evolution during the iTAP, the total sample thickness reduced by about $13 \%$ from $1.5 \mu \mathrm{m}$ to $1.3 \mu \mathrm{m}$. An additional effect of reevaporation at the film surface at temperatures $>275^{\circ} \mathrm{C}$ [15] may also contribute to the thickness loss, which explains the much smaller PLD deposition rate of CdTe at elevated substrate temperatures above $300^{\circ} \mathrm{C}$ that were observed. The lower substrate temperature of $200^{\circ} \mathrm{C}$ in PLD followed with the iTAP is therefore advantageous to minimize the reevaporation. In addition, the CdTe film surface roughness increased consistently with longer iTAP treatment. The as-deposited film has a surface roughness average of $R_{a}=3.8 \mathrm{~nm}$. Larger $R_{a}$ of $16.8 \mathrm{~nm}, 23 \mathrm{~nm}, 26.6 \mathrm{~nm}$, and $35.4 \mathrm{~nm}$ were observed after the iTAP at $450^{\circ} \mathrm{C}$ for $5,10,15$, and $20 \mathrm{~min}$., respectively. Furthermore, the possibility of forming pinholes is increased with longer iTAP time. This can be evaluated from the surface skewness (SSK) of the AFM images, which describes the asymmetry of the height distribution histogram of the sample surfaces. The as-deposited CdTe film has a small possibility of pinholes and a positive value of SSK of 0.14 , which indicates that this film has a flat surface with peaks. After applying the iTAP, the values of SSK become negative numbers of $-0.05,-0.37,-0.53$, and -1.16 for the samples processed with iTAP at $450^{\circ} \mathrm{C}$ for $5,10,15$, and 20 min., respectively. These negative values of SSK indicate that the iTAP processed CdTe films have a bearing surface with holes. Therefore, it is clear from the AFM study that the iTAP is very important step to improve grain growth, which enhances the solar cell parameters significantly as discussed later. However, a longer iTAP duration than the optimal one can lead to material loss and void formations.

The Raman spectra were taken on the CdTe samples by using a WiTec confocal micro-Raman system with a laser excitation wavelength of $\lambda_{\text {exc }}=488 \mathrm{~nm}$ to elucidate the details of the crystallinity and microstructure. Figure 4 compares the Raman spectra of the as-deposited film and four other films treated with different iTAP durations. Four Raman signature peaks can be detected. The peaks at $141 \mathrm{~cm}^{-1}$ and $169 \mathrm{~cm}^{-1}$ correspond to the transverse optical (TO) and the longitudinal optical (LO) phonon of CdTe, respectively [16, 17]. The peak at $292 \mathrm{~cm}^{-1}$ is attributed to (2TO) phonon of CdTe, while the peak at $730 \mathrm{~cm}^{-1}$ can be assigned to $\left(\mathrm{TeO}_{x}\right)$ existence $[18,19]$. The Raman peaks can be studied according to the positions and selection rules of CdTe modes [20]. The LO scattering is only allowed from (100) and (111) planes, while TO scattering is only allowed from (110) and (111). Therefore, the as-deposited film (red), which has both modes, may consist of both hexagonal and cubic planes. After the iTAP, the LO mode became negligibly detectable while the TO mode increased considerably after the iTAP. This, together with the appearing of the high order $2 \mathrm{TO}$ mode after the iTAP, indicates the microstructure improvement and recrystallization of the CdTe films with the iTAP treatment $[19,21]$. Moreover, it can be seen that the as-deposited film has a tellurium oxide $\left(\mathrm{TeO}_{x}\right)$ scattering, which may be attributed to oxidation of the CdTe during the PLD in presence of oxygen residues. This peak reduced with increasing iTAP duration and was completely eliminated after iTAP for more than $5 \mathrm{~min}$.

The normalized transmission spectra $\left(I / I_{0}\right)$ for CdTe films fabricated at different iTAP durations are shown in Figure 5(a). Distinctive differences are present between 


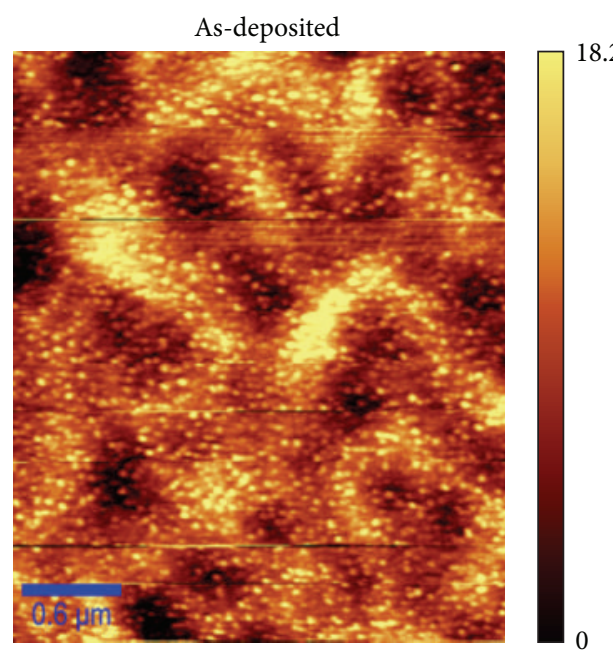

(a)

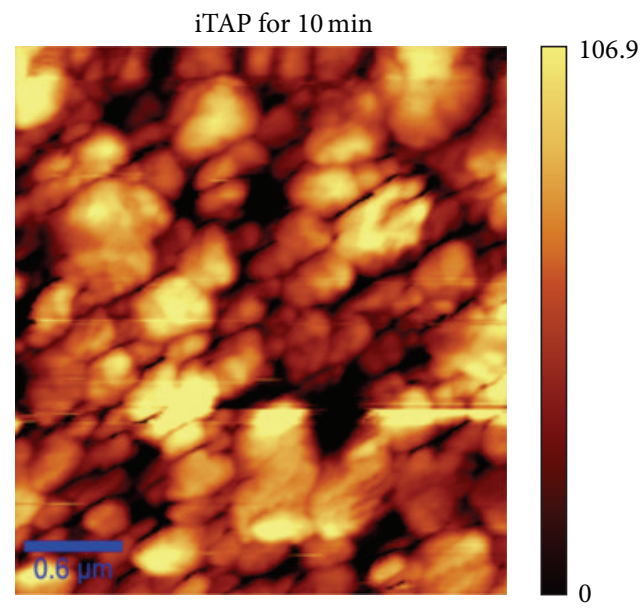

(c)

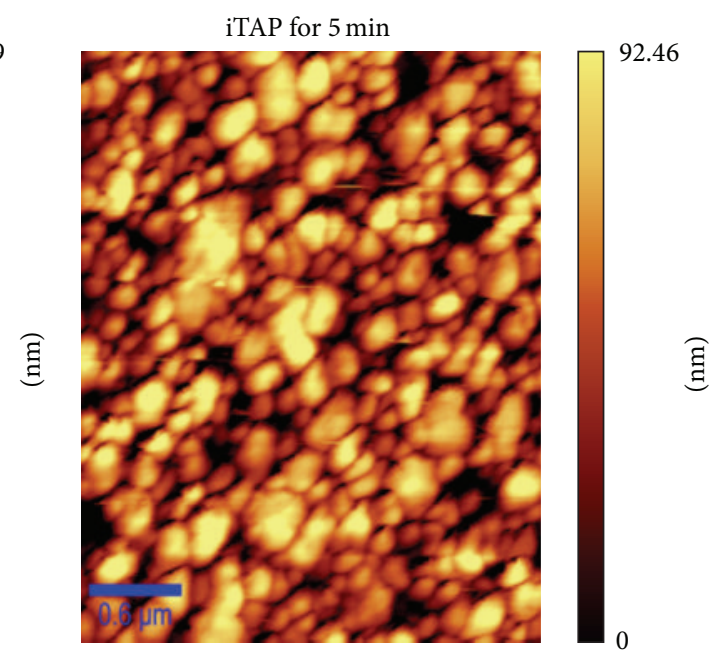

(b)

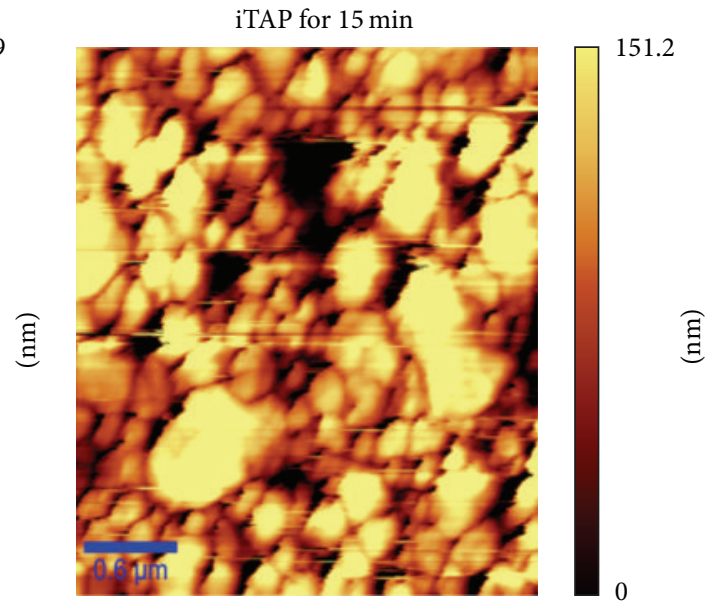

(d)

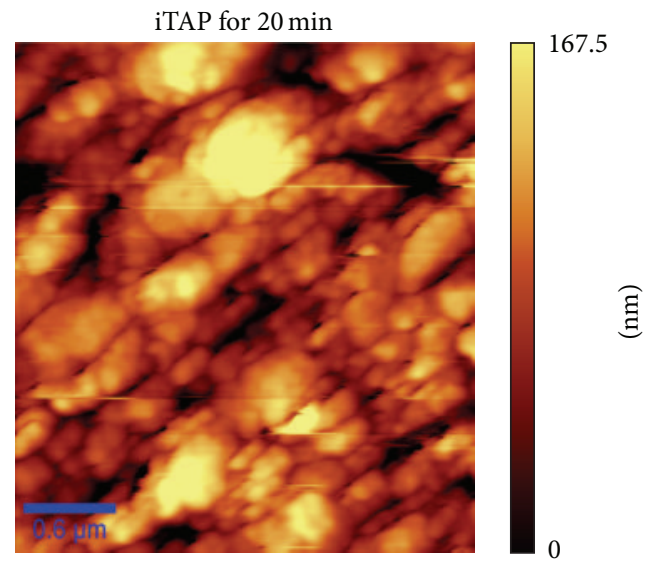

(e)

Figure 3: AFM images taken on CdTe films, as-deposited (a), and with iTAP at $450^{\circ} \mathrm{C}$ for durations of $5 \mathrm{~min}$. (b), $10 \mathrm{~min}$. (c), $15 \mathrm{~min}$. (d), and 20 min. (e). 


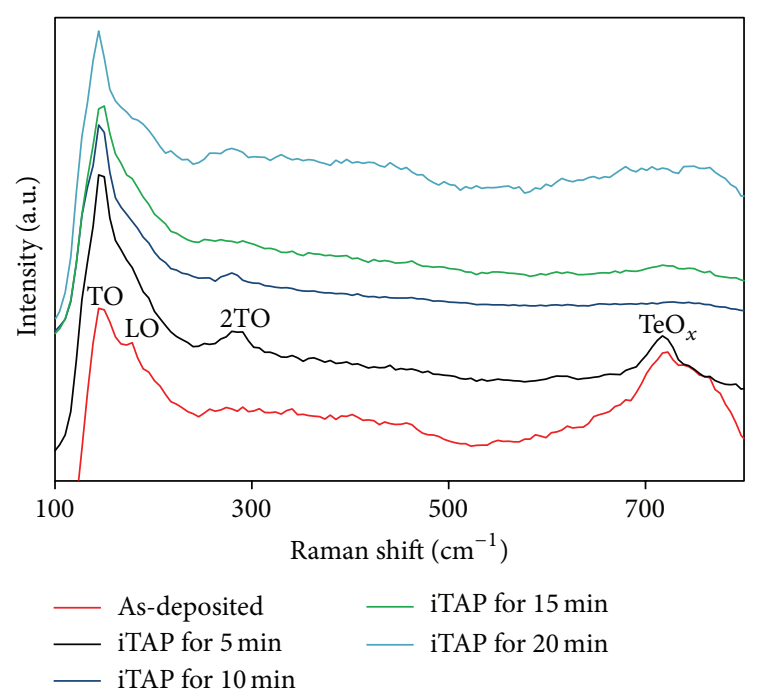

FIGURE 4: Raman spectra of five samples treated with different iTAP durations at $450^{\circ} \mathrm{C}$. Peaks corresponding to the CdTe TO, LO, and $2 \mathrm{TO}$ modes as well as a signature peak of $\mathrm{TeO}_{x}$ can be observed at Raman shifts of $141,169,292$, and $730 \mathrm{~cm}^{-1}$, respectively.

the as-deposited and iTAP treated samples. The former shows poorer transmittance in NIR region and poorer sharpness of the fall near the CdTe absorption edge. This may be observed for several reasons. First, the absorption mechanisms of the non-ideal interband transitions, which are attributed to the small grain growth and existence of many defects in the nano scaled crystal structure [22]. On the other hand, enhanced light scattering and light trapping may occur in films with smaller grain dimensions [13]. The CdTe samples through different iTAP processing have comparable transmittance. The band gap $E_{g}$ of CdTe can be estimated by using the Tauc equation [23]:

$$
\alpha=\left(\frac{k}{h v}\right)\left(h v-E_{g}\right)^{n / 2},
$$

where $k$ is a constant and $n$ is a constant that is equal to 1 for direct gap material such as CdTe. $\alpha$ is the optical absorption coefficient that can be calculated by using Beer-Lambert Law:

$$
I=I_{0} \exp (-\alpha t),
$$

where $I$ and $I_{0}$ are the transmitted and incident radiation intensities, and $t$ is the thickness. Thus, the CdTe band gap can be approximated from the $(\alpha h v)^{2}$ versus $h v$ plots by extrapolating the straight-line portion over the $h v$ axis as shown in Figure 5(b). A considerably smaller $E_{g} \sim 1.36 \mathrm{eV}$ has been estimated for the as-deposited CdTe film, while all iTAP processed CdTe films have comparable $E_{g}$ values close to that of the ideal CdTe bulk of $\sim 1.5 \mathrm{eV}$ (Table 1). The smaller $E_{g}$ of the former may be caused by the incomplete formation of $\mathrm{CdTe}$ structure fabricated at low temperatures. The application of the iTAP seemed effective in facilitating stoichiometric CdTe grain growth and improving its crystallinity.

While the CdTe crystallinity and optical absorption do not seem to vary significantly in the iTAP duration of 5$20 \mathrm{~min}$., the CdTe microstructure evolution as consequence of the grain growth with increasing iTAP duration has a profound effect on the solar cell performance including an increase of the shunt resistance $\left(R_{\mathrm{sh}}\right)$, and consequently an increase of the short current density $\left(J_{\mathrm{sc}}\right)$ and fill factor $(\mathrm{FF})$. In particular, it should be noted that the CdTe crystallization and microstructure evolution process is accompanied with an increase of the $\mathrm{S}$ and Te interdiffusion at the $\mathrm{CdS} / \mathrm{CdTe}$ interface, which leads to reduction of the lattice mismatch and improvements of the depletion region and hence an increase of the open-circuit voltage $\left(V_{\text {oc }}\right)$ [24].

Figure 6(a) compares the dark and illuminated (AM1.5) $J-V$ characteristics of thin film CdTe solar cells with various iTAP durations. The specific performance of different cells is summarized in Table 1 . Higher $V_{\text {oc }}$ was observed on all iTAP processed solar cells as compared to the reference device without iTAP. The increased $V_{\text {oc }}$ may be attributed to the improved $\mathrm{CdS} / \mathrm{CdTe}$ interface through interdiffusion at the interface [25] facilitated by the iTAP, which is supported by the monotonic increase of the $V_{\text {oc }}$ with increasing iTAP duration below $20 \mathrm{~min}$. The best $V_{\mathrm{oc}} \sim 724 \mathrm{mV}$ was obtained at $15 \mathrm{~min}$. of iTAP duration. Interestingly, further increase in iTAP duration to $20 \mathrm{~min}$. resulted in degraded $V_{\text {oc }} \sim 605 \mathrm{mV}$, most probably due to the formation of voids and pinholes as suggested by the AFM data. This suggests the importance of iTAP in controlling the CdS/CdTe microstructure to achieve optimal CdTe grain size, connectivity, and its interface with CdS and to prevent formation of voids and pinholes as shunting paths in the CdS/CdTe solar cells.

Qualitatively, a similar trend in the $J_{\mathrm{sc}}$ and FF as functions of the iTAP duration were also observed despite some quantitative differences. Basically, both $J_{\mathrm{sc}}$ and $\mathrm{FF}$ increased with iTAP duration in shorter time range, followed with a monotonic decrease in longer time range after passing a plateau. The best $J_{\mathrm{sc}}$ of $18.5 \mathrm{~mA} / \mathrm{cm}^{2}$ was observed at the iTAP duration of 5 min., while the best $\mathrm{FF}$ of $52.7 \%$ was at the iTAP duration of $15 \mathrm{~min}$. In Figure 6(b), the external quantum efficiencies (QE) of the same set of devices are depicted as function of wavelength. Considerable improvements in the spectral response of all iTAP treated samples at wavelengths of $520-800 \mathrm{~nm}$ can be clearly seen. This corresponds to an increase in charge carrier generation in the iTAP treated $\mathrm{CdS} / \mathrm{CdTe}$ solar cells, which is anticipated from the crystallinity and microstructure improvements. In particular, the best QE spectrum observed on the sample with an iTAP at $450^{\circ} \mathrm{C}$ for $5 \mathrm{~min}$. seems consistent with the best $J_{\text {sc }}$ value observed on this sample.

Considering the similar optical absorption properties in these iTAP treated samples, the trend in $J_{\text {sc }}$ versus iTAP duration may be attributed to the correlation between iTAP and the follow-up ex situ $\mathrm{CdCl}_{2}$ annealing, leading to the variation in $J_{\text {sc }}$. It is well known that the $\mathrm{CdCl}_{2}$ vapor diffusion into CdTe structure is dictated by the microstructures of the polycrystalline CdTe films, especially the grain boundaries $[26,27]$. Since the grain boundaries offer low-resistance diffusion pathways, the diffusion is most likely to occur more efficiently in smaller-grain CdTe films. This means longer $\mathrm{CdCl}_{2}$ may be necessary for CdTe films with larger grain size for optimal $J_{\text {sc }}$. Therefore, the iTAP and $\mathrm{CdCl}_{2}$ processes are strongly correlated and the optimization will depend on 
TABLE 1: Performances of thin film CdS /CdTe solar cells treated with iTAP at $450^{\circ} \mathrm{C}$ for various durations. ${ }^{*} \mathrm{CdTe}$ thickness of $0.75 \mu \mathrm{m}$, while all others have CdTe thickness of $1.3 \mu \mathrm{m}$.

\begin{tabular}{lcccccc}
\hline iTAP temperature $\left({ }^{\circ} \mathrm{C}\right)$ & iTAP time $(\mathrm{min})$ & $\mathrm{CdTe}$ band gap $(\mathrm{eV})$ & $V_{\text {oc }}(\mathrm{mV})$ & $J_{\mathrm{sc}}\left(\mathrm{mA} / \mathrm{cm}^{2}\right)$ & $\mathrm{FF}(\%)$ & Efficiency $(\%)$ \\
\hline 0 & 0 & 1.40 & 546 & 12.9 & 37 & 2.59 \\
450 & 5 & 1.50 & 691 & 18.5 & 45.5 & 5.8 \\
450 & 10 & 1.50 & 722 & 17.6 & 49.6 & 6.3 \\
450 & 15 & 1.50 & 724 & 16.1 & 52.7 & 6.13 \\
450 & 20 & 1.50 & 605 & 15.3 & 38.1 & 3.52 \\
$450^{*}$ & 15 & 1.45 & 730 & 17.3 & 55.5 \\
\hline
\end{tabular}

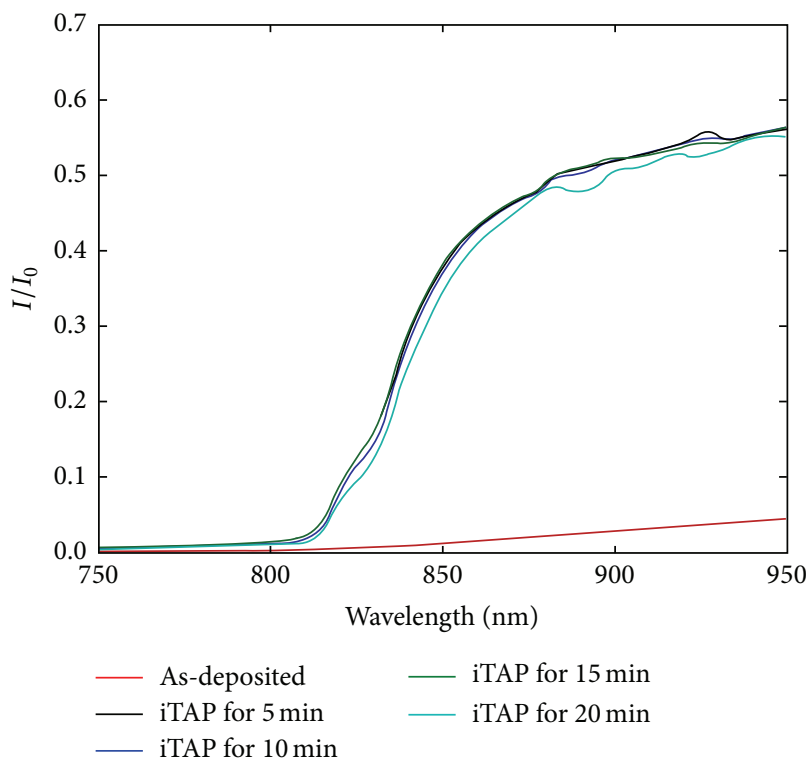

(a)

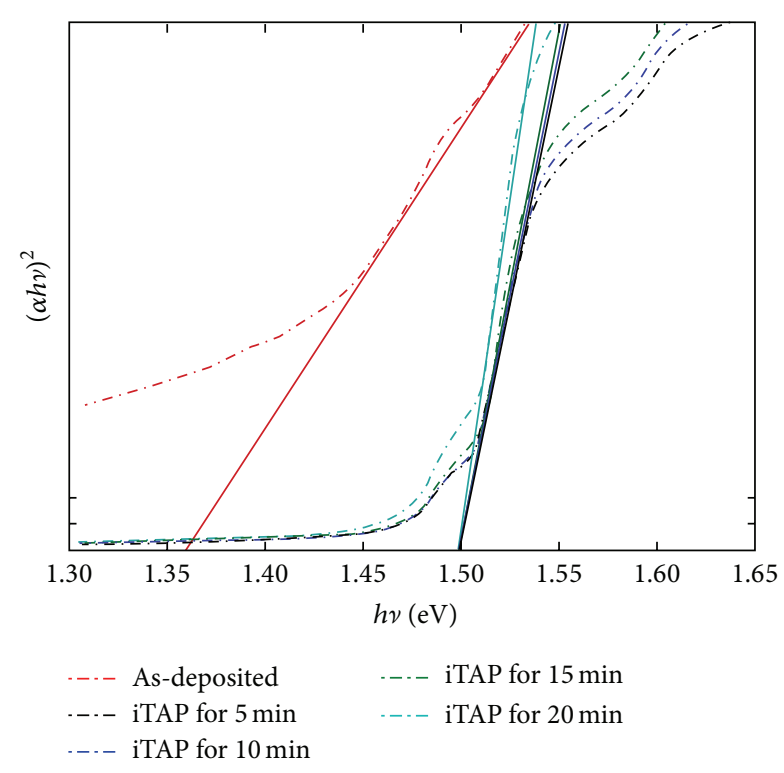

(b)

FIgURE 5: (a) Transmittance spectra and (b) band gap approximation of CdTe thin films treated at different iTAP durations.

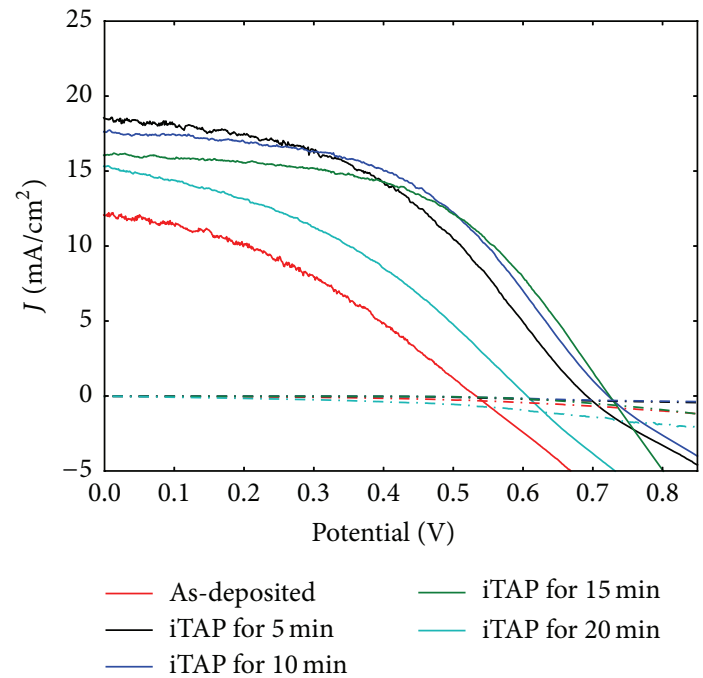

(a)

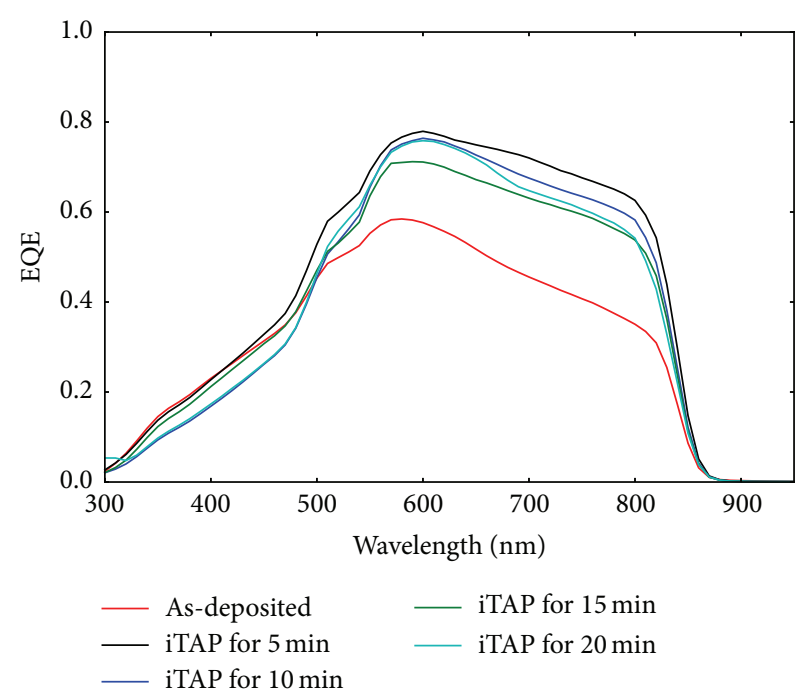

(b)

FIGURE 6: (a) $J$ - $V$ curve characteristics and (b) quantum efficiency curves of thin film CdS/CdTe solar cells with various iTAP durations of $0-20 \mathrm{~min}$. 
the optimal microstructure of CdTe at a given film thickness. For $1.3 \mu \mathrm{m}$ CdTe film thickness, the best power conversion efficiency is $6.3 \%$, which can be further enhanced when the device parameters are further optimized. Nevertheless, this efficiency represents a $>150 \%$ improvement over that on the counterpart samples without the iTAP treatment, suggesting the iTAP process could provide a robust method in controlling the crystallinity and microstructure of CdTe thin film solar cells. In fact, application of iTAP to thinner CdTe (last row in Table 1: CdTe thickness $\sim 0.75 \mu \mathrm{m}$ ) has yielded $7.0 \%$ efficiency, suggesting this approach is feasible to generate high-performance very thin film CdTe solar cells.

\section{Conclusion}

In conclusion, the structural, optical, and electrical properties of CdS $(120 \mathrm{~nm}) / \mathrm{CdTe}(0.75-1.3 \mu \mathrm{m})$ thin film solar cells were studied to understand the effect of the iTAP on the overall performance of the devices including $V_{\mathrm{oc}}, J_{\mathrm{sc}}, \mathrm{FF}$, and QE. The iTAP was carried out in situ at $450^{\circ} \mathrm{C}$ for the variable duration of 5-20 min. immediately after the PLD of CdS/CdTe and has been found to improve the crystallinity and microstructure of CdTe thin films considerably. These improvements resulted in better solar cell performance as illustrated in the higher $V_{\mathrm{oc}}, J_{\mathrm{sc}}, \mathrm{FF}, \mathrm{QE}$, and power conversion efficiency in the solar cells treated with the iTAP. Quantitatively, an optimal window for the iTAP has been identified to yield the best power conversion efficiency of 7.0\%. Considering a strong correlation between the iTAP and ex situ $\mathrm{CdCl}_{2}$ treatment, a precise control of the thin film $\mathrm{CdS} / \mathrm{CdTe}$ microstructure and optoelectronic properties can be achieved through optimization of these processes.

\section{Conflict of Interests}

The authors declare that there is no conflict of interests regarding the publication of this paper.

\section{Acknowledgments}

The authors acknowledge support in part by NASA Contract No. NNX13AD42A, ARO Contract Nos. W911NF-12-1-0412, W911NF-16-1-0029, and NSF Contracts Nos. NSF-DMR1105986, NSF-DMR-1337737, and NSF-DMR-1508494. Alaa Ayad Al-mebir and Ali Kadhim also acknowledge support by the Higher Committee for Education Development in Iraq (HCED) and also by Thi-Qar University in Nassiriya, Iraq.

\section{References}

[1] T. M. Razykov, C. S. Ferekides, D. Morel, E. Stefanakos, H. S. Ullal, and H. M. Upadhyaya, "Solar photovoltaic electricity: current status and future prospects," Solar Energy, vol. 85, no. 8, pp. 1580-1608, 2011.

[2] B. M. Basol, "Electrodeposited CdTe and HgCdTe solar cells," Solar Cells, vol. 23, no. 1-2, pp. 69-88, 1988.

[3] K. Vamsi Krishna, V. Dutta, and P. D. Paulson, "Effect of electric field on spray deposited CdTe thin films," Thin Solid Films, vol. 444, no. 1-2, pp. 17-22, 2003.
[4] T. Aramoto, S. Kumazawa, H. Higuchi et al., "16.0\% efficient thin-film CdS/CdTe solar cells," Japanese Journal of Applied Physics, vol. 36, no. 10, pp. 6304-6305, 1997.

[5] V. Plotnikov, X. Liu, N. Paudel, D. Kwon, K. A. Wieland, and A. D. Compaan, "Thin-film CdTe cells: reducing the CdTe," Thin Solid Films, vol. 519, no. 21, pp. 7134-7137, 2011.

[6] N. Amin, T. Isaka, A. Yamada, and M. Konagai, "Highly efficient $1 \mu \mathrm{m}$ thick CdTe solar cells with textured TCOs," Solar Energy Materials and Solar Cells, vol. 67, no. 1-4, pp. 195-201, 2001.

[7] J. M. Ball, M. M. Lee, A. Hey, and H. J. Snaith, "Low-temperature processed meso-superstructured to thin-film perovskite solar cells," Energy \& Environmental Science, vol. 6, no. 6, pp. 17391743, 2013.

[8] P. Hu, B. Li, L. Feng et al., "Effects of the substrate temperature on the properties of CdTe thin films deposited by pulsed laser deposition," Surface and Coatings Technology, vol. 213, pp. 8489, 2012.

[9] B. Li, J. Liu, G. Xu, R. Lu, L. Feng, and J. Wu, "Development of pulsed laser deposition for CdS/CdTe thin film solar cells," Applied Physics Letters, vol. 101, no. 15, Article ID 153903, 2012.

[10] C. Ding, Z. Ming, B. Li, L. Feng, and J. Wu, "Preparation and characterization of pulsed laser deposited CdTe thin films at higher FTO substrate temperature and in $\mathrm{Ar}+\mathrm{O}_{2}$ atmosphere," Materials Science and Engineering B: Solid-State Materials for Advanced Technology, vol. 178, no. 11, pp. 801-806, 2013.

[11] P. R. Willmott and J. R. Huber, "Pulsed laser vaporization and deposition," Reviews of Modern Physics, vol. 72, no. 1, pp. 315$328,2000$.

[12] J. T. Cheung and H. Sankur, "Growth of thin films by laserinduced evaporation," Critical Reviews in Solid State and Materials Sciences, vol. 15, no. 1, pp. 63-109, 1988.

[13] S. Chun, K.-S. Han, J.-H. Shin, H. Lee, and D. Kim, "Fabrication and characterization of CdTe nano pattern on flexible substrates by nano imprinting and electrodeposition," Microelectronic Engineering, vol. 87, no. 11, pp. 2097-2102, 2010.

[14] C. S. Ferekides, D. Marinskiy, V. Viswanathan et al., "High efficiency CSS CdTe solar cells," Thin Solid Films, vol. 361, pp. 520-526, 2000.

[15] S. K. Pandey, U. Tiwari, R. Raman et al., "Growth of cubic and hexagonal CdTe thin films by pulsed laser deposition," Thin Solid Films, vol. 473, no. 1, pp. 54-57, 2005.

[16] C. Ancora, P. Nozar, G. Mittica et al., "Properties of CdTe layers deposited by a novel method-Pulsed Plasma Deposition," http://arxiv.org/abs/1103.4539.

[17] M. Kimata, T. Suzuki, K. Shimomura, and M. Yano, "Interdiffusion of In, Te at the interface of molecular beam epitaxial grown CdTe InSb heterostructures," Journal of Crystal Growth, vol. 146, no. 1-4, pp. 433-438, 1995.

[18] N. Dewan, V. Gupta, K. Sreenivas, R. S. Katiyar, and N. Dewan, "Growth of amorphous $\mathrm{TeO}_{x}(2 \leq x \leq 3)$ thin film by radio frequency sputtering," Journal of Applied Physics, vol. 101, no. 8, Article ID 084910, 2007.

[19] D. Wang, Z. Hou, and Z. Bai, "Study of interdiffusion reaction at the CdS/CdTe interface," Journal of Materials Research, vol. 26, no. 5, pp. 697-705, 2011.

[20] B. Ghosh, S. Hussain, D. Ghosh, R. Bhar, and A. K. Pal, "Studies on CdTe films deposited by pulsed laser deposition technique," Physica B: Condensed Matter, vol. 407, no. 21, pp. 4214-4220, 2012.

[21] T. M. Razykov, N. Amin, M. A. Alghoul et al., "Effect of the composition on physical properties of CdTe absorber layer 
fabricated by chemical molecular beam deposition for use in thin film solar cells," Journal of Applied Physics, vol. 112, no. 2, Article ID 023517, 2012.

[22] M. Soliman, A. B. Kashyout, M. Shabana, and M. Elgamal, "Preparation and characterization of thin films of electrodeposited CdTe semiconductors," Renewable Energy, vol. 23, no. 3-4, pp. 471-481, 2001.

[23] H. T. Grahn, Introduction to Semiconductor Physics, World Scientific, Singapore, 1999.

[24] B. E. McCandless, L. V. Moulton, and R. W. Birkmire, "Recrystallization and sulfur diffusion in $\mathrm{CdCl} 2$-treated $\mathrm{CdTe} / \mathrm{CdS}$ thin films," Progress in Photovoltaics: Research and Applications, vol. 5, no. 4, pp. 249-260, 1997.

[25] T. H. Myers, J. F. Schetzina, S. T. Edwards, and A. F. Schreiner, "Effect of surface preparation on the $77 \mathrm{~K}$ photoluminescence of CdTe," Journal of Applied Physics, vol. 54, no. 7, pp. 4232-4234, 1983.

[26] P. G. Shewmon, Diffusion in Solids, J Williams Book Company, Jenks, Okla, USA, 1983.

[27] H. C. Chou, A. Rohatgi, N. M. Jokerst, E. W. Thomas, and S. Kamra, "Copper migration in CdTe heterojunction solar cells," Journal of Electronic Materials, vol. 25, no. 7, pp. 1093-1098, 1996. 

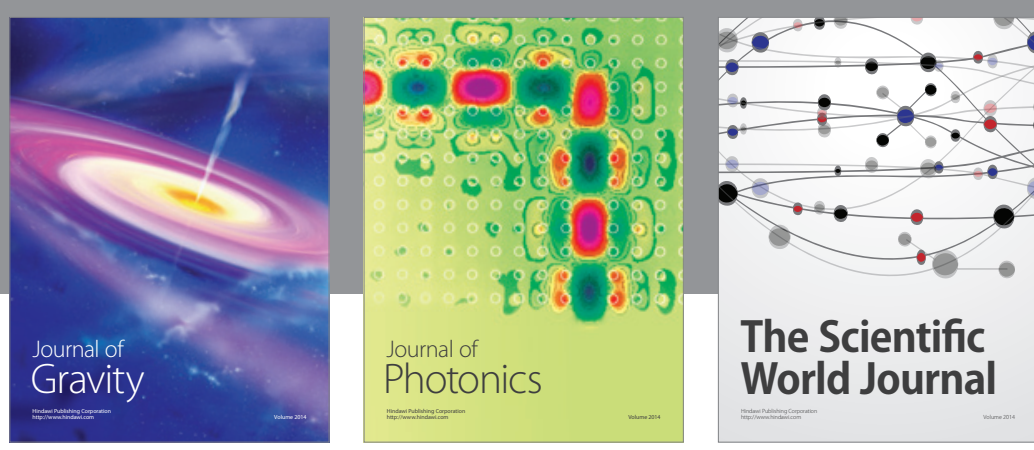

The Scientific World Journal
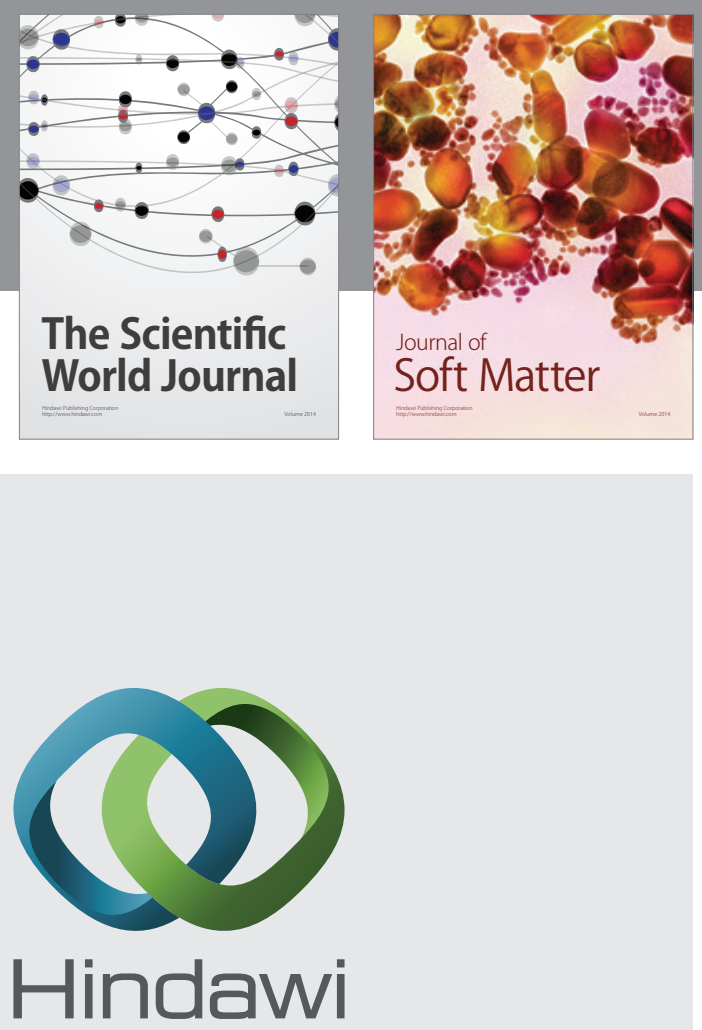

Submit your manuscripts at

http://www.hindawi.com

nternational Journal of

Statistical Mechanics
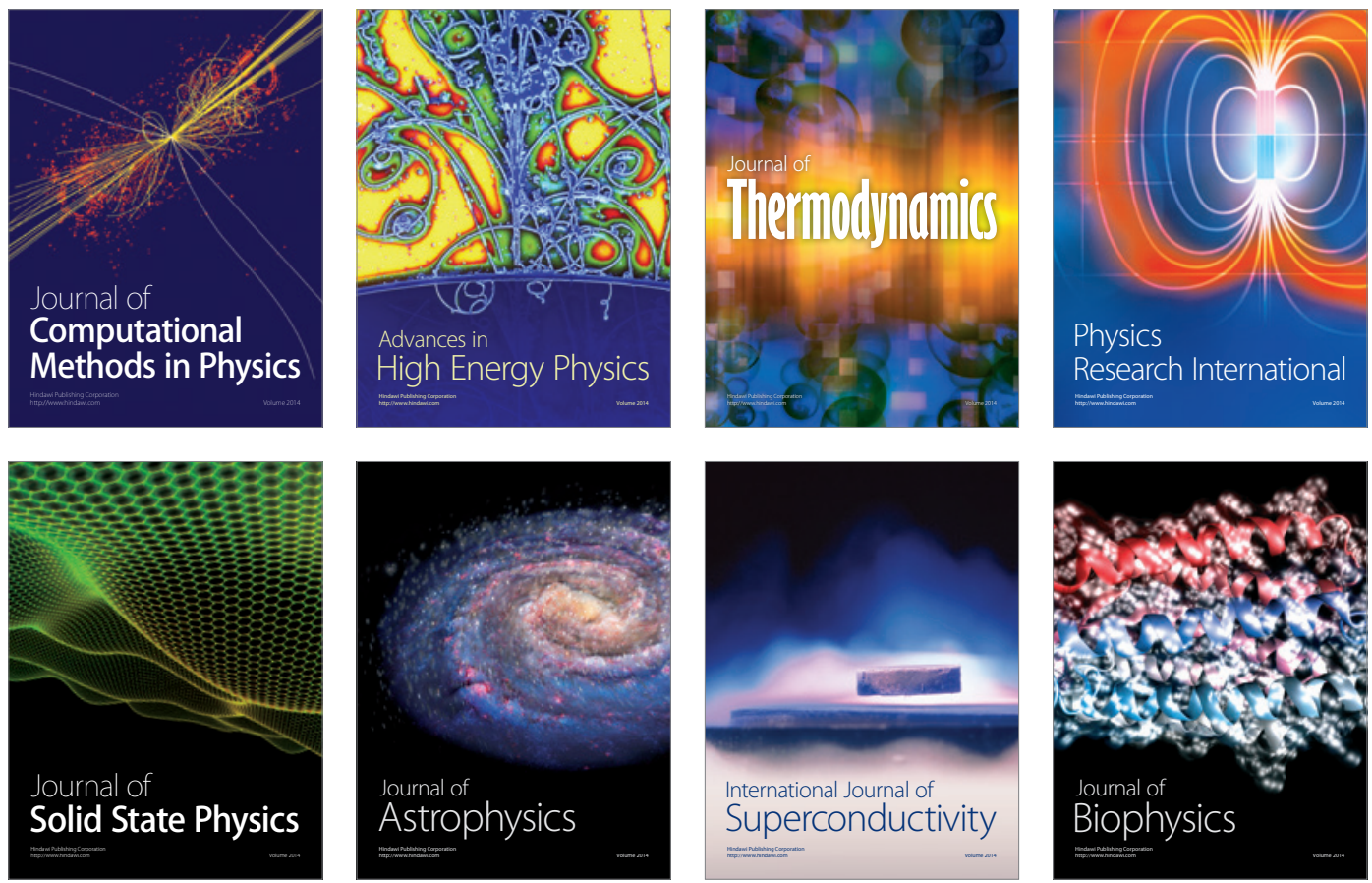
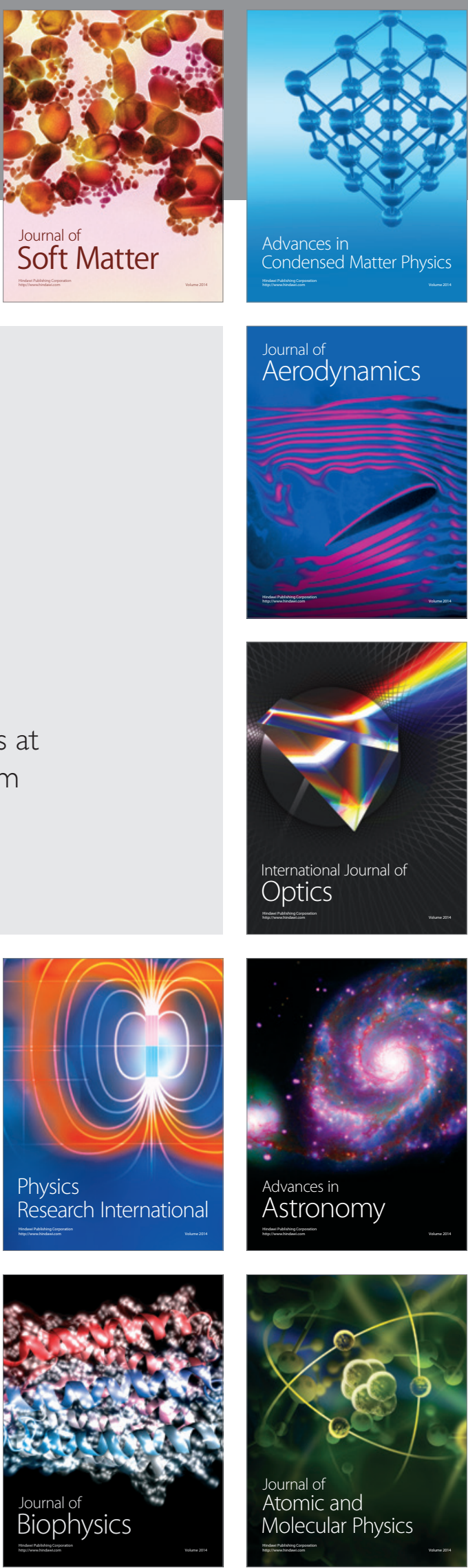